\title{
Pengolahan Lahan Berkontur Pada Kawasan Ekowisata, Cijaringao, Bandung
}

\author{
Utami, Dwi Nurhayati, Fatimah Aulia Dina, Emalia Yulistia F. \\ Program Studi Arsitektur, Fakultas Arsitektur dan Desain, \\ Institut Teknologi Nasional Bandung \\ Email: utami_heryadin@yahoo.com
}

\begin{abstract}
ABSTRAK
Pentingnya konservasi alamiah suatu kawasan pada saat ini merupakan suatu pemikiran yang penting ditengah isu penataan kawasan yang ramah lingkungan. Mengingat banyaknya pembangunan di suatu kawasan yang dilakukan tanpa mempertimbangkan aspek alamiah tapak. Salah satu kasus yang cukup penting diulas adalah pengolahan lahan berkontur. Bandung Utara memiliki karakteristik topografi tanah dengan kemiringan yang cukup besar bahkan beberapa memiliki kecuraman yang ekstrim. Berkembangnya kawasan Bandung Utara menjadi objek wisata atau villa pada saat ini merupakan suatu hal yang kadang kala tidak diperhatikan lagi. Skala prioritas pada aspek bisnis, menjadikan beberapa karakteristik lahan kontur alamiah mengalami perombakan besar-besaran. Akibatnya lingkungan alamiah menjadi rusak, erosi bahkan longsor. Penelitian terhadap kawasan ekowisata Cijaringao, kawasan Bandung Utara yang memiliki karakteristik topografi berkontur merupakan objek studi yang sesuai dengan tema tersebut. Tujuannya adalah menganalisa pengolahan dan pemanfaatan kontur pada fungsi wisata. Metode kuantiatif - normatif digunakan sebagai analisis pengolahan lahan kontur dengan mengujinya terhadap standar ideal pengolahan perancangan pada lahan berkontur. Harapannya,penelitian ini dapat membuka wawasan para perencana dalam merancang fasilitas (built environment) pada lahan berkontur.
\end{abstract}

Kata Kunci : Kontur, lingkungan alamiah, ekowisata, Cijaringao ecoland

\begin{abstract}
The importance of natural conservation of an area at this time is an important thought amid the issue of environmentally friendly zoning. Given the large number of developments in an area that are carried out without considering the natural aspects of the site. One of the important cases to review is contour land management. North Bandung has a characteristic topography of the land with a fairly large slope and some even have extreme steepness. The development of the north bandung area to become a tourist attraction or a villa at this time is something that is sometimes overlooked. The scale of priority in the business aspect has made some of the characteristics of the natural contour land underwent a major overhaul. As a result, the natural environment is damaged, erosion and even landslides. Research on the ecotourism area of Cijaringao, North Bandung which has a contour topographical characteristic is an object of study in accordance with this theme. The aim is to analyze the processing and utilization of contours in the tourism function. The quantitative - normative method is used as a contour tillage analysis by testing it against the ideal standard of design processing on contoured land. It is hoped that this research can open the insights of planners in designing built facilities on contoured land.
\end{abstract}

Keywords: Contours, natural environment, ecotourism, Cijaringao ecoland 


\section{PENDAHULUAN}

Kontur adalah salah satu keadaan topografi bumi dimana permukaan tanah memiliki ketinggian yang berbeda dengan karakteristik permukaan tanah yang unik. Lahan berkontur memiliki daya tarik tersendiri salah satunya adalah view. Potensi itu dimanfaatkan sebagai tempat wisata. Pemanfaatan lahan berkontur untuk fungsi lahan tempat wisata, harus mempertimbangkan aspek karakteristik alami tapak. Menjadi pertimbangan utama adalah pemanfaatan kontur eksisting dalam perencanaan tempat wisata. Berbagai pengolahan lahan berkontur dapat dilakukan dengan cara melakukan cut, fill atau cut and fill. Pengolahan lahan secara berlebihan tidak baik untuk lahan, karena dapat meningkatkan resiko terjadinya tanah longsor. Maka dari itu seorang arsitek memiliki peran penting dalam mempertimbangkan kondisi eksisting lahan berkontur yang sudah ada dengan tetap memenuhi tuntutan kebutuhan fungsional.

Cijaringao Ecoland merupakan kawasan ekowisata, kawasan tersebut memanfaatkan lahan berkontur sebagai fasilitas wisatanya. Penataan fasilitas yang terdapat di Cijaringao Ecoland dibentuk sedemikian rupa agar tidak merusak kondisi lahan kawasan konservasi. Dilihat dari hal tersebut penulis tertarik untuk melakukan penelitian dan mengidentifikasi seperti apa pemanfaatan dan pengolahan lahan berkontur terhadap penataan lanskap yang diterapkan di Cijaringao Ecoland dengan seluruh aktivitas dan fasilitas penunjang.

Tujuan dari penulisan ini adalah untuk memahami bagaimana pemanfaatan lahan berkontur terhadap penataan lanskap pada kawasan ekowisata Cijaringao Ecoland.

\section{METODOLOGI}

Metodologi penelitian yang digunakan yaitu kuantiatif - normatif digunakan sebagai analisis pengolahan lahan kontur dengan mengujinya terhadap standar ideal pengolahan perancangan pada lahan berkontur. Metode ini digunakan dalam proses analisis grading plan kawasan Cijaringao Ecoland, yang berupa perbandingan persentasi tanah yang dipapas/gali (cut) dan tanah yang di urug (fill) terhadap kondisi eksisting tanah sebelumnya. Standar kemiringan tanah ideal yang dapat difungsikan secara efektif sesuai dengan aktifitas yang terjadi.

\section{HASIL DAN PEMBAHASAN}

Pembahasan pengolahan lahan berkontur pada fasilitas wisata publik di Cijaringao ini dapat lebih jelas dilihat pada tabel analisis berikut ini.

Tabel Analisis Pengolahan Kontur

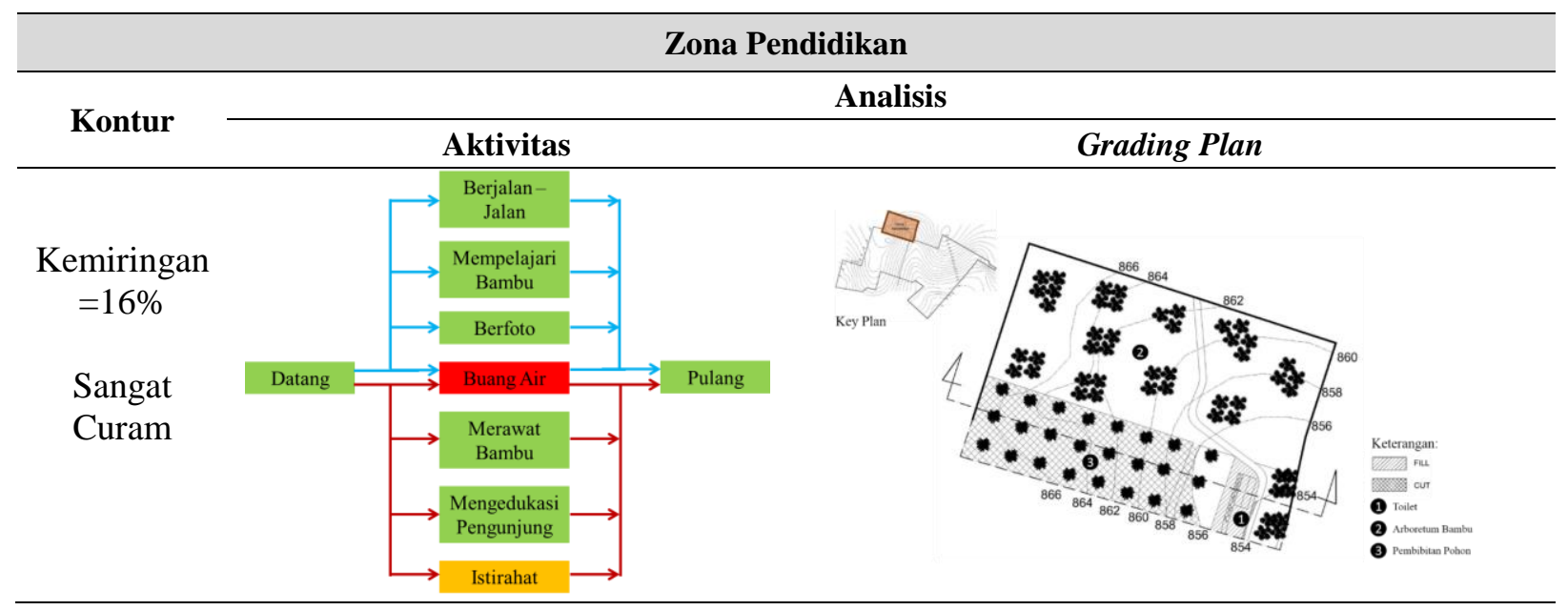




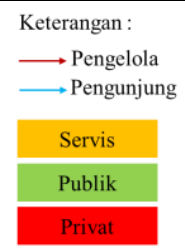

\begin{abstract}
Aktivitas :
Edukasi Bambu

Merawat Bambu

Buang Air
\end{abstract}

\section{Analisis terhadap aktivitas:}

Kemiringan lahan sangat curam, menyesuaikan dengan aktivitas pada zona yang berupa area arboretum maka pengolahan lahan dilakukan pada area yang terdapat fasilitas penunjang pada zona tersebut.

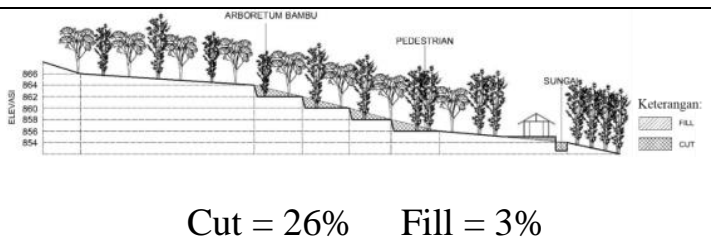

Analisis terhadap grading plan:

Pengolahan berdasarkan penanaman vegetasi dan peletakan fasilitas penunjang. Terdapat 2 cara penanaman vegetasi, tanaman bambu ditanam menyesuaikan dengan kontur lahan sementara vegetasi lainnya ditanam pada lahan menyerupai teras bangku sehingga membutuhkan pengolahan lahan berupa pemangkasan atau cut. Sementara dengan adanya toilet di zona ini yang membutuhkan lahan datar, maka mengalami penambahan atau urugan tanah atau fill.
Kemiringan
$=37 \%$

(Sangat

Curam)

Kemiringan

$=6.7 \%$

(Landai)

\section{Zona Rekreasi}

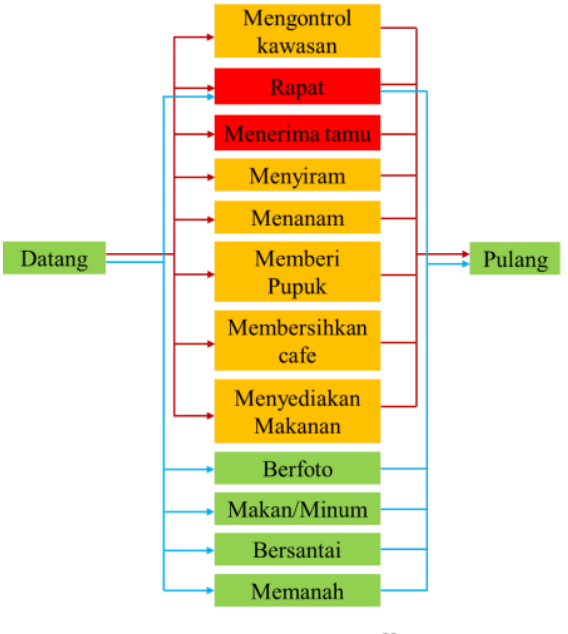

Keterangan :

$\longrightarrow$ Pengelola $\longrightarrow$ Pengunjung

\section{Servis}

Publik

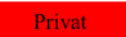

Aktivitas :

Mengkontrol kawasan

Berkebun

Memanah

Menyajikan Hidangan

Menyantap Hidangan

Berfoto

Analisis terhadap aktivitas:

Pada lahan yang memiliki kemiringan cukup terjal harus

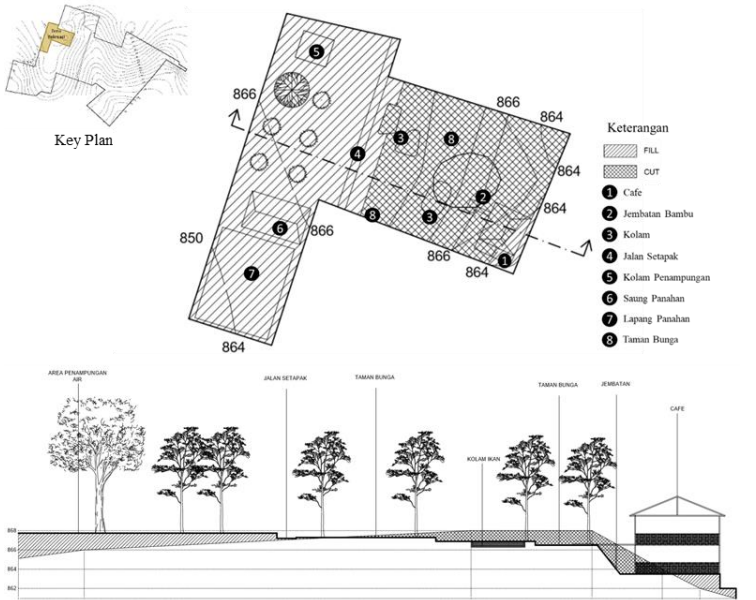

Cut $=39 \% \quad$ Fill $=55 \%$

Analisis terhadap grading plan:

Terdapat fasilitas yang memerlukan lahan datar yang menyebabkan dilakukannya proses cut and fill seperti pada area memanah dan area penampungan air. Sedangkan pada area café grading plan terjadi pemangkasan cukup banyak yang di buat oleh petani sebagai saung peristirahatan pada saat belum menjadi kawasan Cijaringao Ecoland. 
dilakukan untuk meminimalkan

bencana erosi.

\section{Zona Pembibitan}

Kemiringan

$=21 \%$

(Sangat

Curam)

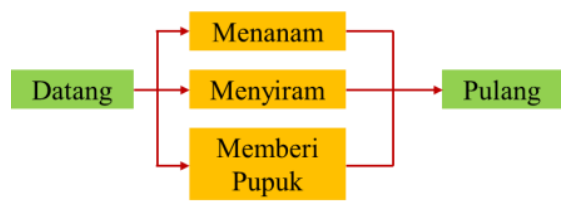

Keterangan :

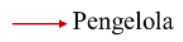

\begin{tabular}{|l|}
\hline Servis \\
\hline Publik \\
\hline Privat \\
\hline
\end{tabular}

\section{Aktivitas :}

Menanam tanaman

Menyiram

Memberi Pupuk

\section{Analisis terhadap aktivitas:}

Pada lahan yang memiliki kemiringan cukup terjal harus dilakukan untuk meminimalkan bencana erosi.
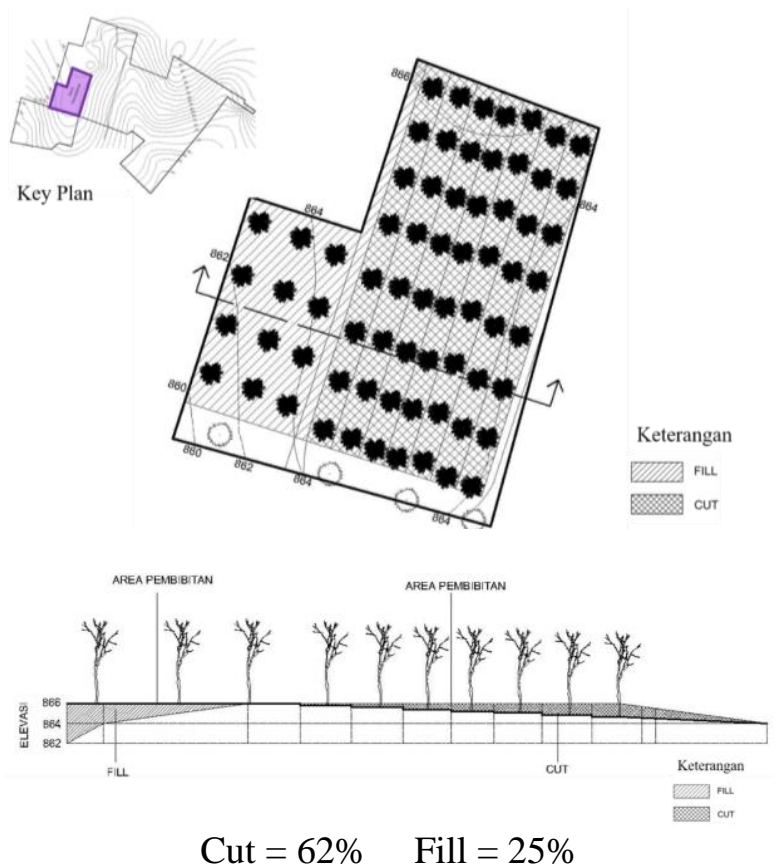

Analisis terhadap grading plan:

Zona pembibitan ini didisain untuk meminimalisasi terjadinya bencana erosi, sehingga desain zona pembibitan dibuat kedalam bentuk teras bangku, dengan tujuan untuk mengurangi terjadinya erosi maka zona pembibitan mengalami cut and fill tanah.
Kemiringan

$=15 \%$

(Sangat

curam)

\section{Zona Perkebunan}

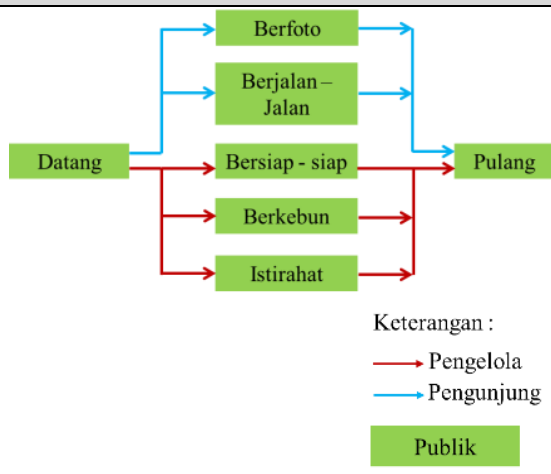

Aktivitas :

Berkebun
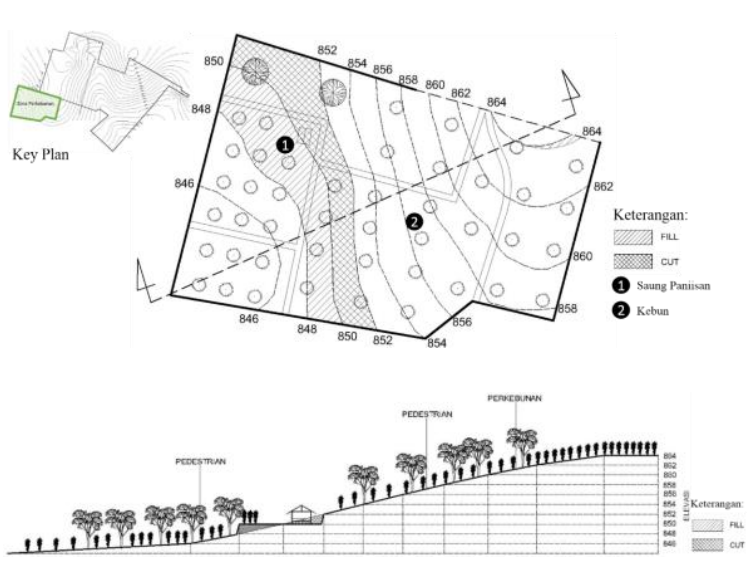

$$
\mathrm{Cut}=11 \% \quad \text { Fill }=12 \%
$$

Analisis terhadap aktivitas: 
Kemiringan lahan sangat curam, tetapi menyesuaikan dengan aktivitas primer pengguna yang hanya melakukan kegiatan berkebun maka pengolahan lahan dilakukan pada area fasilitas penunjang pada zona.

\section{Analisis terhadap grading plan:}

Pengolahan lahan hanya dilakukan pada peletakan saung paniisan pada zona ini. Adanya saung paniisan maka terdapat pengolahan lahan berupa cut dan fill agar posisi lahan saung datar, sementara area perkebunan hanya memanfaatkan kemiringan lahan sebagai area penanaman vegetasi kebun.

\section{Zona Peternakan}

Kemiringan

$=23.3 \%$

(Sangat

curam)

Kemiringan

$=22.7 \%$

(Sangat

curam)
Aktivitas :

Beternak

Berkebun

Bermain

Berfoto

\section{Analisis terhadap aktivitas:}

Lahan yang sangat curam tidak cocok untuk peternakan. Sehingga perlu adanya pengolahan lahan.
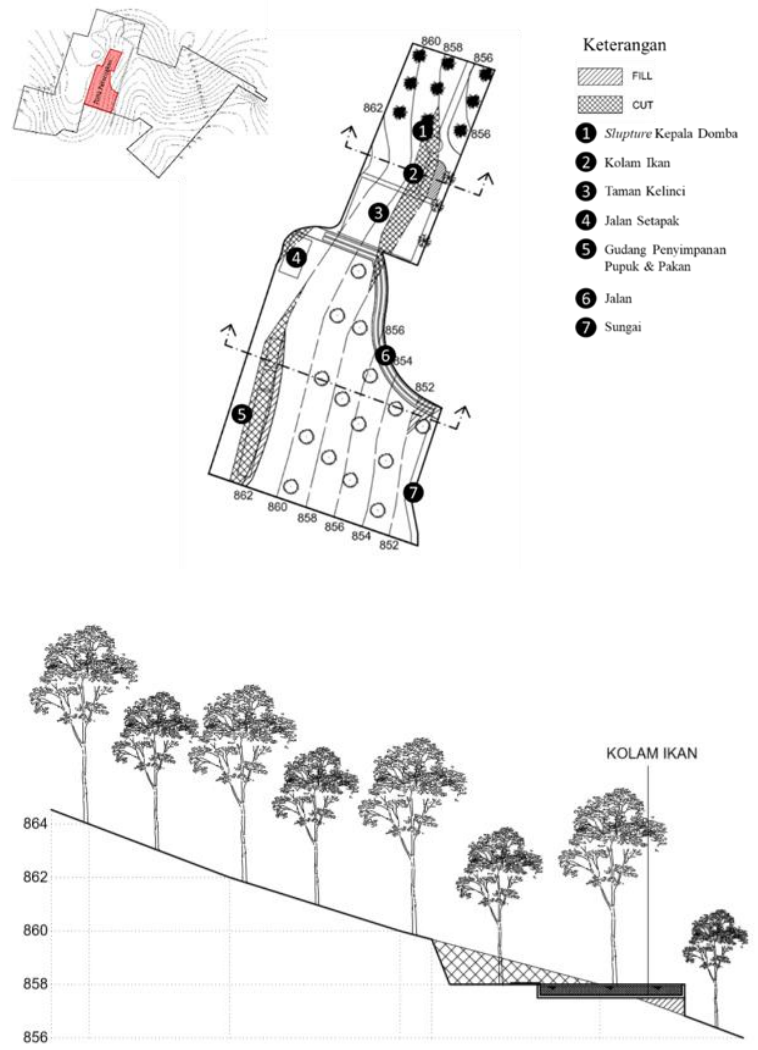

Cut $=10 \% \quad$ Fill $=2.8 \%$

Analisis terhadap grading plan:

Pada area ini lahan yang di cut and fill adalah lahan yang terbangun oleh bangunan dan kolam ikan hal ini dikarenakan kondisi lahan yang sangat curam untuk tempat hewan ternak. Sedangkan area lainnya sebagian besar masih mempertahankan konturnya.

\section{Zona Camping Ground}




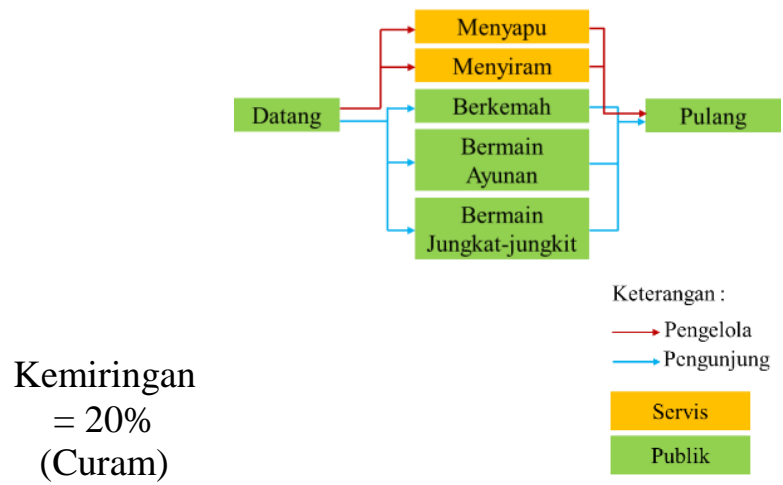

Aktivitas:

Berkemah

\section{Analisis terhadap aktivitas:}

Lahan yang terlalu curam tidak cocok untuk kegitan berkemah, sehingga diperlukannya pengolahan lahan lebih lanjut.
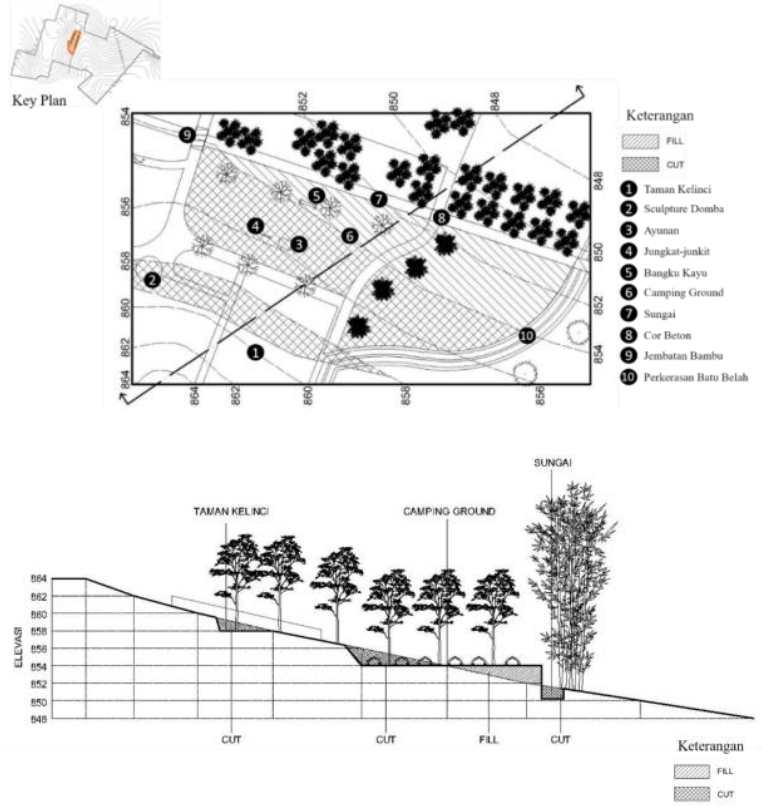

$$
\text { Cut }=56 \% \quad \text { Fill }=44 \%
$$

\section{Analisis terhadap grading plan:}

Zona camping ground pada kawasan Cijaringao Ecoland ini berupa dataran terbuka, area camping ground ini dikhususkan sebagai fasilitas perkemahannya saja, dan membutuhkan area yang cukup datar namun, karena posisinya berada di kontur yang sangat curam sehingga area camping ground banyak melakukan grading plan.

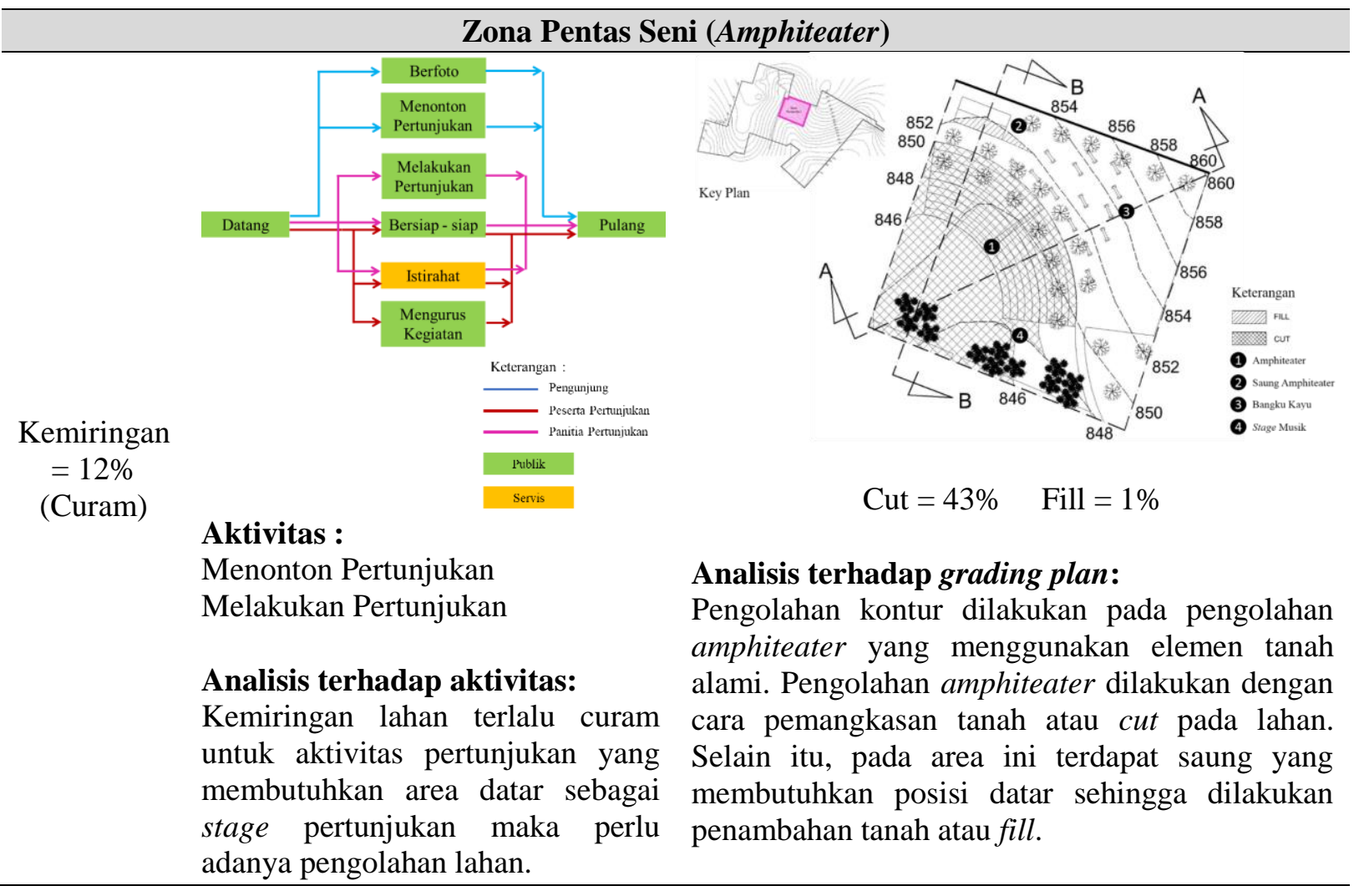




\section{Zona Pentas Seni (Area Adu Domba)}

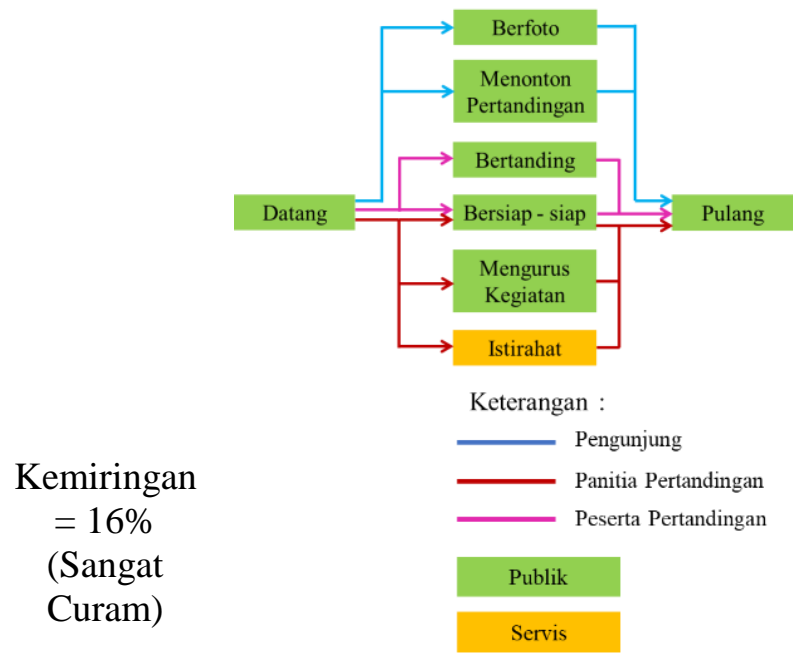

Aktivitas :

Bertanding Adu Domba

Menonton Pertandingan

\section{Analisis terhadap aktivitas:}

Kemiringan lahan sangat curam untuk aktivitas pertandingan adu domba, sehingga perlu adanya pengolahan lahan.

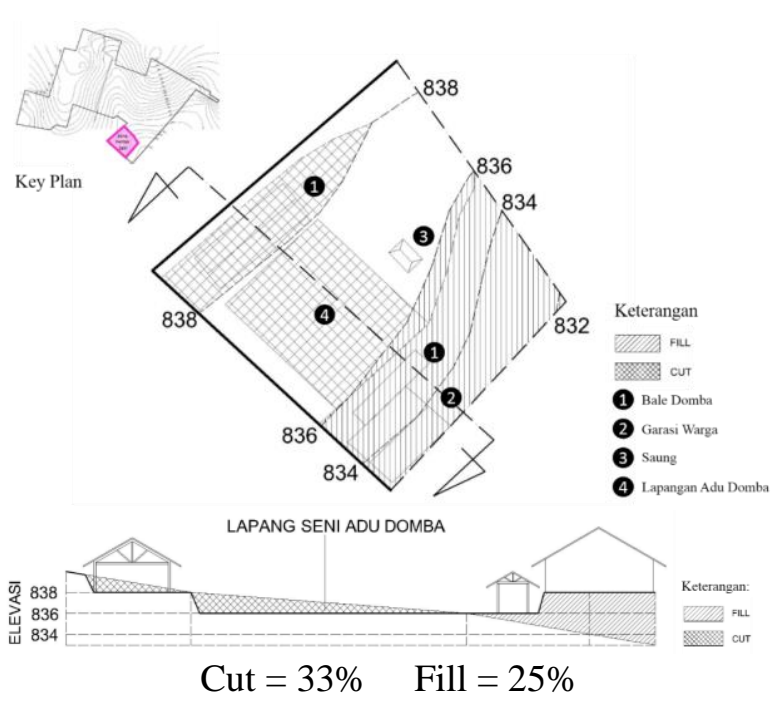

Analisis terhadap grading plan:

Penataan lapangan adu domba terdapat pengolahan kontur berupa pemangkasan tanah atau cut karena membutuhkan posisi lahan yang datar. Selain itu, terdapat pengolahan tanah berupa penambahan atau fill pada area bale dan bangunan garasi.
Kemiringan

$=21 \%$

(Sangat

Curam)
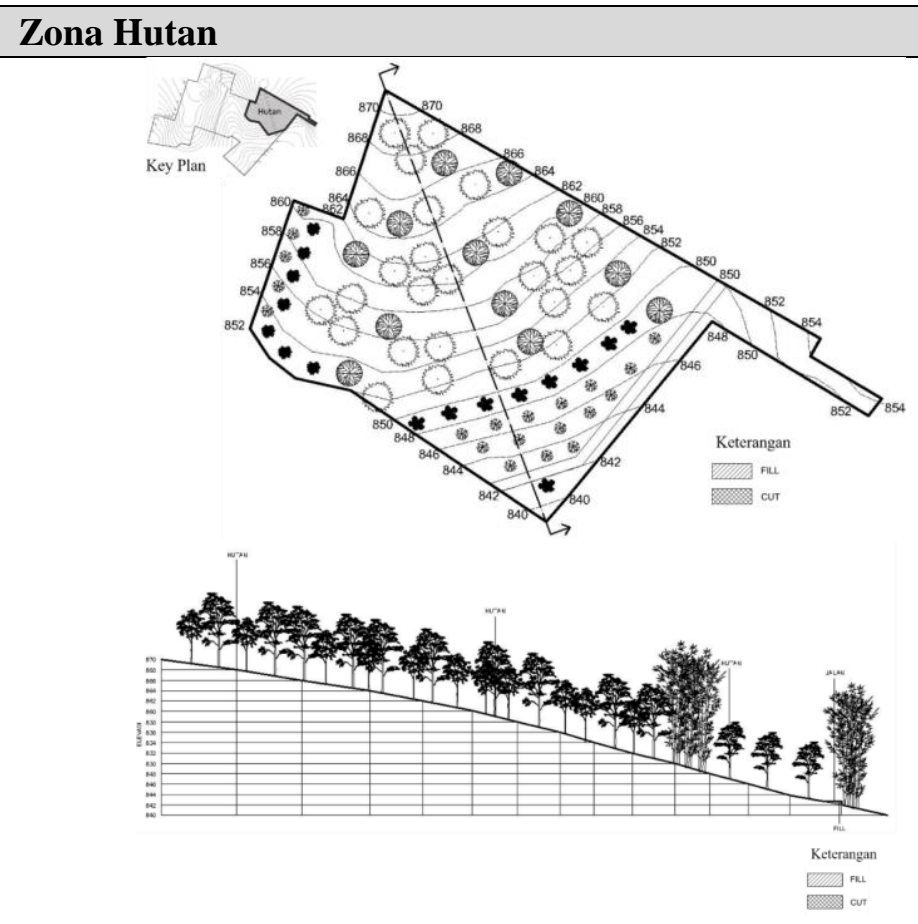

Cut $=-\quad$ Fill $=-$

Analisis terhadap grading plan:

Zona hutan pada kawasan Cijaringao Ecoland ini berupa lahan yang masih belum dirancang sehingga kontur lahan masih belum terolah, begitu 
juga dengan kondisi vegetasi yang terdapat di dalam area tersebut. Karena lahan masih belum dirancang, maka belum ada grading plan yang dilakukan pada zona hutan.

\section{Zona Kesenian}

Kemiringan

$=21 \%$

(Sangat

Curam)

\section{Aktivitas :}

Pelatihan dan Berkumpul

Istirahat

Buang Air

\section{Analisis terhadap aktivitas:}

Kemiringan lahan terlalu curam untuk aktivitas pelatihan, sehingga perlu adanya pengolahan lahan atau pendesainan bangunan harus disesuaikan dengan keadaan kontur yang ada.
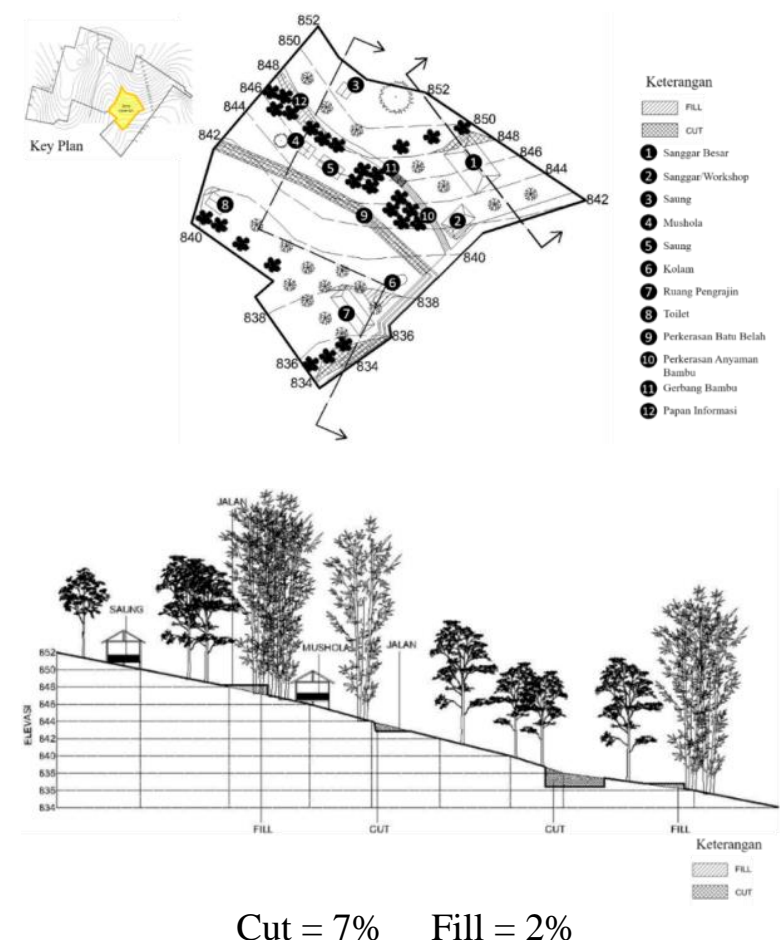

Analisis terhadap grading plan:

Pengolahan lahan berkontur terhadap penataan elemen hardscape pada zona kesenian dilakukan proses cut and fill, hanya pada bagian bangunan tertentu, Bangunan yang mengalami pengolahan lahan adalah bangunan ruang pengrajin, sanggar/workshop, serta sanggar besar, selain bangunan terdapat juga pengolahan lahan pada aksesibilitas untuk masuk kedalam site, terutama pada perkerasan batu belah, pada akses tersebut dilakukan cut pada lahan.

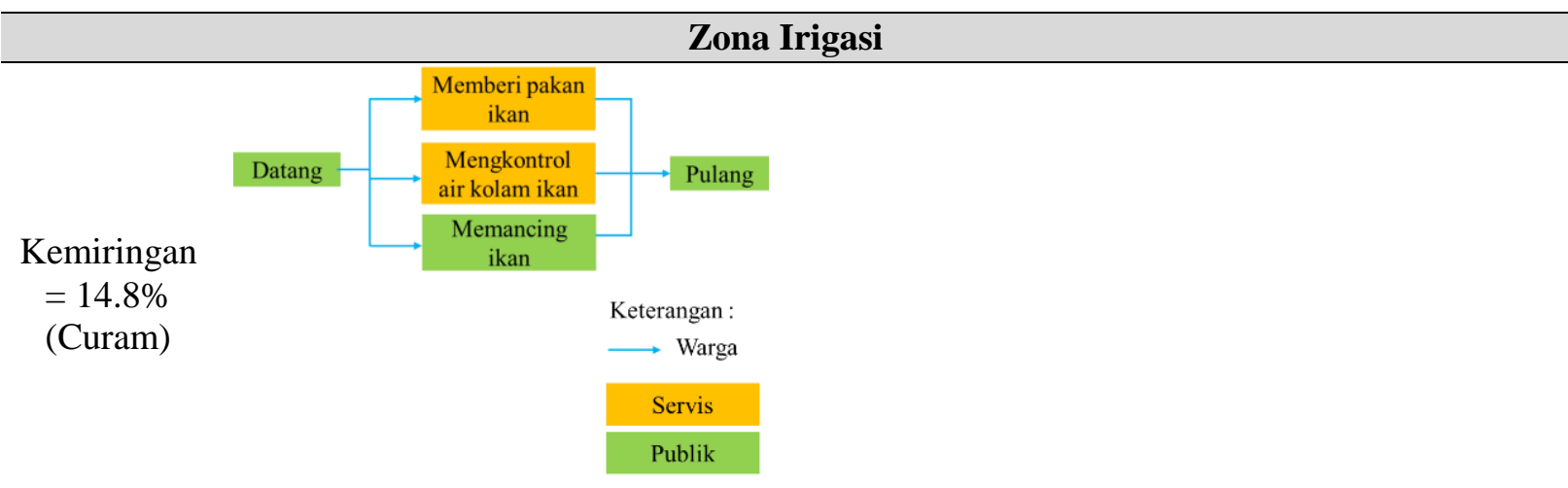

Aktivitas : 


\section{Memancing}

Berkebun

\section{Analisis terhadap aktivitas:}

Kemiringan lahan curam tidak cocok untuk dijadikan area memancing. Perlu adanya pengolahan khusus terhadap kontur untuk membuat kolam pemancingan.

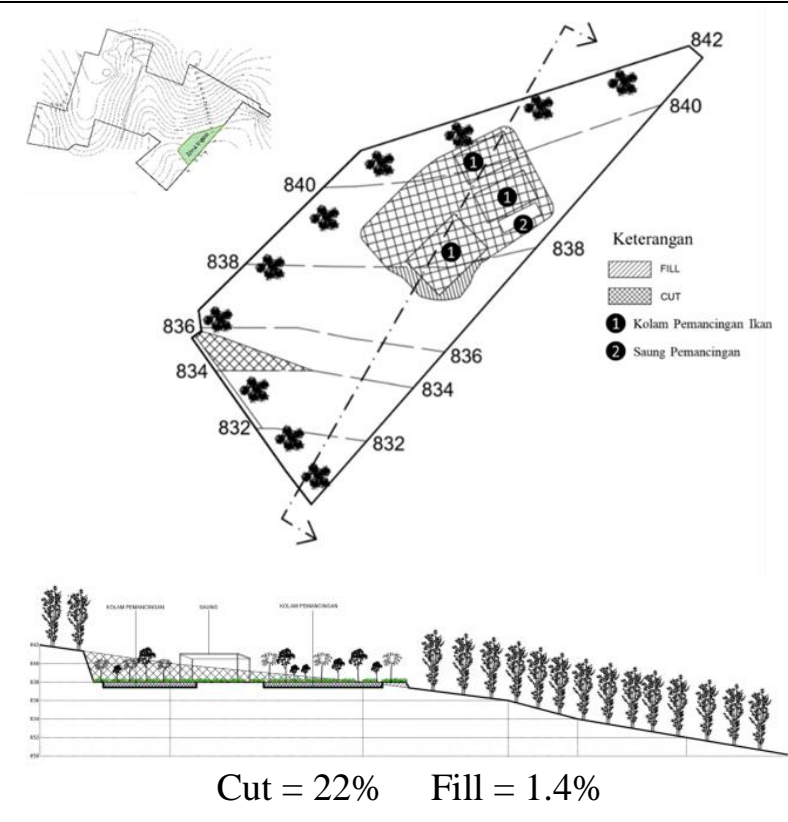

Analisis terhadap grading plan:

Untuk membuat sebuah kolam ikan memerlukan lahan yang di gali dengan kontur yang datar. Lokasi zona irigasi berada dilahan yang curam sehingga perlu adanya pengolahan lahan cut and fill.

\section{Zona Parkir (Di Dalam)}

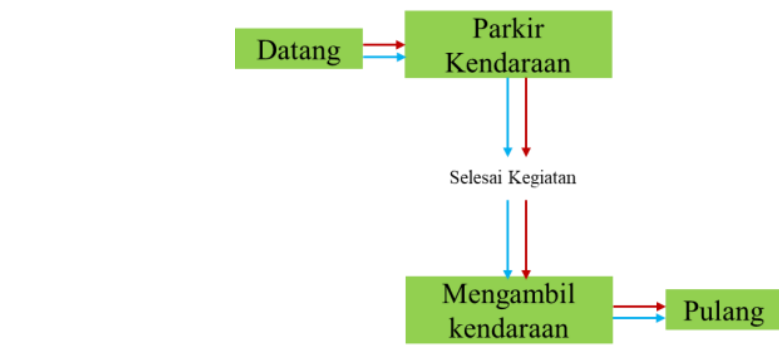

Kemiringan

$=8.7 \%$

(Landai)
Keterangan :
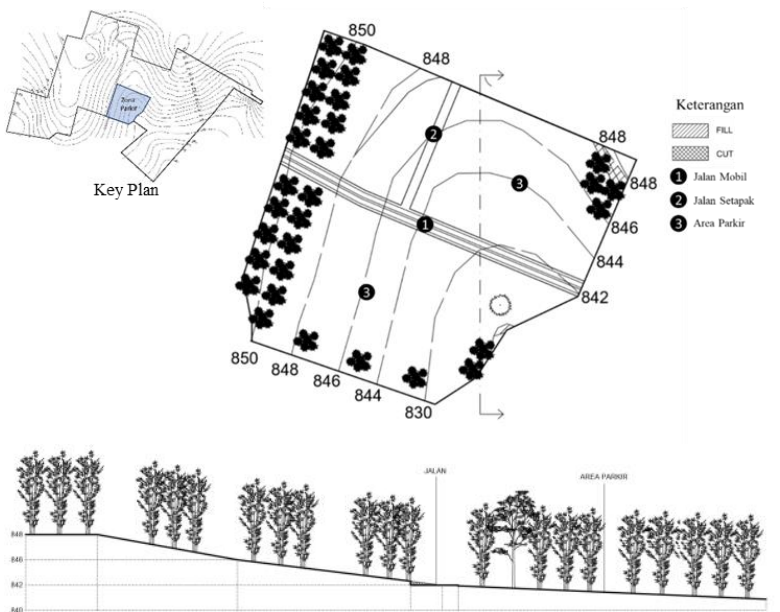

Cut $=0.6 \% \quad$ Fill $=1.5 \%$

Analisis terhadap aktivitas:

Lahan cukup landai untuk area parkiran. Sehingga tidak perlu adanya pengolahan berlebihan pada lahan.

\section{Analisis terhadap grading plan:}

Pada area parkir terdapat grading plan yang sedikit karena lahan yang sudah termasuk kategori landai. Pada jalur sirkulasinya terdapat pula proses pengolahan lahan dengan cara di cut. 


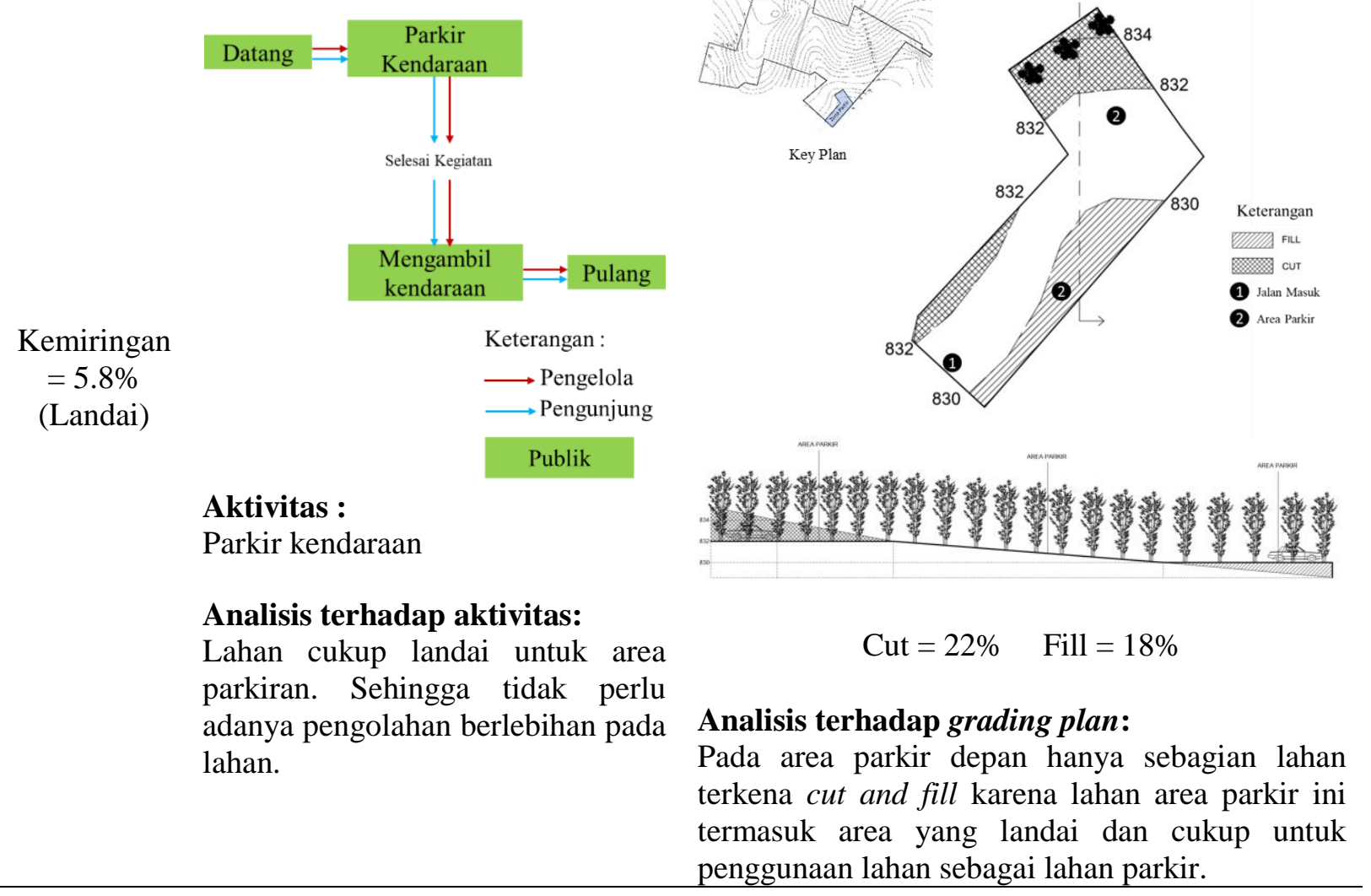

\section{SIMPULAN}

Penataan lanskap kawasan wisata Cijaringao Ecoland mempertahankan kondisi eksisting dan karakteristik topografi tanah. Proses desain tapak memiliki pendekatan wawasan lingkungan dan ramah lingkungan. Konstrain pengolahan tapak juga dilakukan secara simultan terhadap pemenuhan tuntutan fasilitas sebagai wadah aktifitas wisata publik. Aktivitas yang bersifat pasif dipilih lokasinya pada lahan dengan kemiringan yang datar. Sedangkan aktivitas dengan kategori aktif, dipilih pada lahan kemiringan lahan yang lebih fleksibel. Artinya dapat ditempatkan pada lahan curam, tidak harus pada lahan kemiringan landai. Pengolahan lahan berkontur dan elemen lanskap yang berada di Cijaringao Ekowisata, ini menggunakan konsep papas (cut) serta urug (fill) tanah. Pengolahan lahan yang lebih banyak dilakukan di dalam lahan menggunakan teknik pemangkasan tanah (cut). Kondisi ini disebabkan terdapatnya elemen air yang membutuhkan lahan yang datar dan dalam. Proporsi pengolahan di lahan wisata Cijaringao Ecoland mengunakan teknik pemapasan (cutting) tanah sebanyak $21 \%$ dan $11 \%$ dilakukan pengurugan (filling) tanah.

\section{DAFTAR PUSTAKA}

[1] Iwan Nugroho.,(2011). "Ekowisata Dan Pembangunan Berkelanjutan”, Pustaka Pelajar, Yogyakarta.

[2] Booth, Norman K., (1990). Basic Elements Of Landscape Architectural Design. Waveland Press,Inc., Illinois. 
[3] Anonim., (2014). Rating System For Sustainable Land Design and Development”. D.C. Green Business Certification Inc. Washington.

[4] Pemerintah Provinsi Jawa Barat., (2011). Peraturan Gubernur Jawa Barat tentang Pengendalian Pemanfaatan Ruang Kawasan Bandung Utara, Pemerintah Provinsi Jabar, Bandung.

[5] Galeri Pustaka., (2013). Pengertian Lanskap Secara Umum; <galeripustaka.com/2013/03/pengertian-lanskap-secara-umum.html;diakses tanggal 17 Oktober 2019.

[6] Thomas R. Ryan. (2011). Detailing for Landscape Architects. Aesthetics and Function. John Wiley \& Sons, New Jersey, USA

[7] Tagalumbang M Herlangga., (2015). Green Resort di Bakauheni, Pengembangan Bakauheni Sebagai Resort berbasis Sustainable Sites, Bakauheni

[8] Hakim R., (2000). Komponen Perancangan Arsitektur Lanskap, Bumi Aksara, Jakarta.

[9] Yusuf K., Pengertian Kontur dan Kemiringan Lereng, <http://kasmatyusufgeo10.blogspot.com/2012/11/Pengertian-kontur-dan-kemiringanlereng.html>diakses tanggal 8 Oktober 2019

[10] Rustam Hakim, (2012). Komponen Perancangan Arsitektur Lansekap. Bumi Aksara, Jakarta. 